\title{
Semantic Web Regulatory Models: Why Ethics Matter
}

\author{
Philosophy and Technology (Springer Journal) \\ Special issue on Information Societies, Ethical Enquiries (2014) \\ DOI: $10.1007 / \mathrm{s} 13347-014-0170-y$
}

\author{
Pompeu Casanovas \\ pompeu.casanovas@uab.cat \\ UAB Institute of Law and Technology \\ Department of Political Science and Public Law \\ Universitat Autònoma de Barcelona \\ Cerdanyola del Vallès, Barcelona 08193, Spain \\ Tlf. 34935812235 \\ Fax 34935812988 \\ pompeu.casanovas@rmit.edu.au \\ Centre for Applied Social Research \\ School of Global, Urban and Social Studies \\ RMIT University, City Campus \\ 124 LaTrobe Street | Melbourne Vic 3000
}

\begin{abstract}
The notion of validity fulfils a crucial role in legal theory. In the emerging Web 3.0, Semantic Web languages, legal ontologies, and Normative Multi-agent Systems (nMAS) are designed to cover new regulatory needs. Conceptual models for complex regulatory systems shape the characteristic features of rules, norms and principles in different ways. This article outlines one of such multilayered governance models, designed for the CAPER platform, and offers a definition of Semantic Web Regulatory Models (SWRM). It distinguishes between normative-SWRM and institutional-SWRM. It also compares existing principles in Privacy by Design, Linked Open Data (LOD), Legal Information Institutes (LII), and Online Dispute Resolution (ODR). The article concludes by proposing the notion of Relational Law to summarize the ethical dimension of SWRM. Ethics are the only regulatory way to constitute a global space, out of the jurisdictional public domain set by national, international or transnational law, and opposed to the private one.
\end{abstract}

KEYWORDS. Validity, legal theory, Semantic Web Regulatory Models (SW), legal ontologies, Normative Multi-agent Systems (nMAS), Privacy by Design (PbD), Linked Open Data (LOD), Online Dispute Resolution (ODR)

\section{INTRODUCTION}

Collaboration between humans and computers is key in addressing societal challenges. Democracy and the rule of law can and should benefit from this synergy. The AI \& Law 
community has been working on that for the past twenty-five years (Bench-Capon et al. 2012). With the expansion of the Internet into the Semantic Web and the Internet of Things, law and programming have become components of intertwined complex regulatory frameworks. I currently refer to these new frameworks as Relational Law (Casanovas, 2012, 2013).

Relational is a shared property that emerges from the existing economic, social, and political bonds among citizens as Internet users. Regulatory systems are the social side of relational law, the way how "humanity in the loop" evolves interactively from "the human in the loop" (Hendler and Berners-Lee, 2010). As long as regulatory systems contain procedural ways to manage and solve conflicts, they shape relational systems of justice too. Relational justice can therefore be defined as the type of justice emerging from the different dialogical practices and strategies within technological situated contexts (Casanovas and Poblet, 2008).

Both regulatory systems and relational justice can be monitored by regulatory models. A regulatory model is the specific normative suit encased by platforms built up to monitor a regulatory system, the specific structure of principles, values, norms and rules guiding technical protocols, multi-layered relation of organizations (multi-layered governance) and the interoperability of computer languages. When a regulatory model is based on semantic technologies, we can speak of Semantic Web Regulatory Models (SWRM), to be applied to platforms, web services, semantic web services, or the next stage of the Internet of (linked) Services. ${ }^{1}$

This article is organized as follows. Section 2 briefly summarize SW and legal theory to situate the discussion; sections 3 and 4 define and make the distinction between normative SWRM and institutional SWRM; section 5 shows the example of a model built to regulate a platform for police exchange and interoperability; in section 6 the comparison between several theoretical domains shows that the role ethics plays in SWRM is far from simple; section 7 contends that the multidimensional public space in which they operate is mainly dialogical and it emerges from interaction and a decentralized production of rules and norms. Some conclusions will be eventually displayed in section 8 .

\section{THE SEMANTIC WEB AND LEGAL THEORY}

The Semantic Web (SW) can be conceived not only as a web of documents, but as a web of data. "The vision of the Semantic Web is to extend principles of the Web from documents to data" (Herman, 2009). Structured as a layered cake, ${ }^{2}$ semantic languages annotate, relate and model data. Data is represented through standards like XML [eXtended Mark-up Language], RDF [Resource Description Framework], RDFS [RDF Schema] and OWL [Ontology Web Language]. SPARQL [SPARQL Protocol and RDF Query Language] allows the search of structured data (in RDF, RDFS and OWL). It is a

\footnotetext{
${ }^{1}$ A Semantic Web Service fulfils different functions - discovery, selection, composition, and execution - "to enable seamless interoperation between systems whereby human intervention is kept at a minimum". For a taxonomy of approaches and SWS languages, see Slimani (2013). But see Pedrinaci and Domingue (2010) on their actual performance on the Web.

${ }^{2}$ See the last version of the famous SW 'cake' or stack of languages by T. Berners-Lee at http://www.w3.org/2007/03/layerCake.png
} 
standard search language to perform graph queries and to build up SW applications. ${ }^{3}$ The result leads to information management and processing, as knowledge - hypertext links, connection of objects, and information retrieval from the Web using not keywords (terms), but concepts. Data integration, resource discovery and classification, cataloguing, content rating and, in later times, knowledge sharing and exchanging through intelligent software agents are some of these applications.

At the same time, the Internet has evolved through the so-called Web 2.0, the social web. James Hendler (2009) plotted in the following way the relationship between Web 2.0, the social web, and 3.0, SW technologies powering large-scale Web applications: "Web 3.0 extends current Web 2.0 applications using Semantic Web technologies and graph-based, open data" (Fig. 1.)

\begin{tabular}{|c|c|}
\hline \multicolumn{2}{|c|}{ Web 3.0} \\
\hline Web 2.0 & $\begin{array}{c}\text { Semantic Web (RDFS, } \\
\text { OWL) }\end{array}$ \\
\cline { 2 - 2 } & $\begin{array}{c}\text { Linked Data (RDF, } \\
\text { SPARQL) }\end{array}$ \\
\hline
\end{tabular}

Fig. 1. Source: Hendler (2009)

When focused onto the legal field, this broad vision encounters legal knowledge, i.e. the result of conceptualization, interpretation and reasoning based not only on legal norms, but on (judicial and political) decision making and rule patterns emerging from social practices and economic behaviour. Legal data, then, is produced, stored, retrieved and reused in complex scenarios with a plurality of players with different and often competing roles — citizens, consumers, companies, NGOs, civil rights activists, government rulers, parliament representatives, judges, lawyers... - at different levels of organization, scope and political strength. This situation is broadly referred in the political science literature as the legal side of e-governance or IT-governance.

The implementation, application and enforcement of legal systems constitute an interdependent field into whom SW technologies can be ran in a structured way only if these real scenarios are assumed and taken into account. One of the objectives of the present article is showing how both IT-governance and legal systems can be faced from the Semantic Web perspective without losing content. Is there a reasonable way to bridge those different languages and legal theoretical approaches?

This depends on how "legal knowledge" is defined. As early as in 1994, André Valente and Joost Breuker referred similarly to this problem as "the missing link between legal theory and AI \& law". Legal-core computational ontologies have helped since then to bridge the gap leaning onto legal theory assumptions about norms, rules, principles, values, directives... However, twenty years later and despite the longstanding efforts, we

\footnotetext{
${ }^{3}$ http://www.w3.org/TR/rdf-sparql-query/
} 
do not have one but many core-ontologies with different functionalities, ends and purposes. ${ }^{4}$

In recent times, rule interchange languages for the legal domain have been flourishing to give an answer to the same question and make law interoperable: the RuleMarkup Language (RuleML) ${ }^{5}$, Semantics of Business Vocabulary and Business Rules (SBVR) ${ }^{6}$, the Semantic Web Rule Language (SWRL) ${ }^{7}$, the Rule Interchange Format $(\mathrm{RIF})^{8}$, and the Legal Knowledge Interchange Format (LKIF) ${ }^{9}$. Gordon, Governatori and Rotolo (2009) have selected main legal components as requirements to be complied with by interchange languages. ${ }^{10}$ But they correctly assert that there is no language which can satisfy all of them at the same time (ibid., p. 294).

This is not a negligible outcome, for there are several approaches to legal ontology building (Sartor et al. 2011). I will contend that a hybrid perspective taking into account phenomena that are different in nature - e.g. linked open data; the conceptual structure of legal data, metadata and rules, or the conceptual structure of networked governance- would better match the link. Put it differently, in the Web 3.0 law turns out to be relational, deployed thorough multilayered governance regulatory systems. The "missing link" does not occur now between legal theory and AI \& Law, but between the plurality of options from which law can be theorized and put in practice, and the plurality of perspectives that the new generation of Semantic Web technologies opens up. That is to say, between what I will call $n$-Semantic Web Regulatory Models and i-Semantic Web Regulatory Models.

\section{N-SEMANTIC WEB REGULATORY MODELS}

There are different conceptions of what rules and norms mean as well. In computer science, rules are commonly divided into production rules and declarative rules. ${ }^{11}$ In

\footnotetext{
${ }^{4}$ See Casellas (2011) for a broad summary, esp. chapter 3. I will come back to ontologies in section 7.

${ }^{5}$ RuleML (Rule Markup Language, which has also become a Rule Modeling Language and a Rule MetaLogic) is a unifying family of XML-serialized rule languages spanning across all industrially relevant kinds of Web rules. It is mainly focused on industry rather than on academy uses. Vid. http://www.ruleml.org.

${ }^{6}$ The SBVR defines the vocabulary and rules for documenting the semantics of business vocabularies, business facts, and business rules; as well as an XMI schema for the interchange of business vocabularies and business rules among organizations and between software tools. Vid. http://en.wikipedia.org/wiki/Semantics_of_Business_Vocabulary_and_Business_Rules

${ }^{7}$ Vid. http://en.wikipedia.org/wiki/Semantic_Web_Rule_Language The specification was submitted in May 2004 to the W3C by the National Research Council of Canada, Network Inference (since acquired by webMethods), and Stanford University in association with the Joint US/EU ad hoc Agent Markup Language Committee. Cfr. http://www.w3.org/Submission/SWRL/ (latest version, 2004).

${ }^{8}$ The Rule Interchange Format (RIF) is a W3C Recommendation. RIF is part of the infrastructure for the SW, along with SPARQL, RDF and OWL Vid. http://www.w3.org/TR/2013/NOTE-rif-primer20130205/

${ }^{9}$ LKIF was built in the EU Project ESTRELLA (2006-2008), and its goal was to develop an interchange format for models of legal norms.

${ }^{10}$ They have selected the following components: isomorphism, reification, rule semantics, defeasibility, contraposition, contributory reasons or factors, rule validity, legal procedures, normative effects, and values. This summary is reproduced slightly modified in Balke et al. (2013, 11 and ff.), in which the authors explicitly assert that these aspects "contribute to classifying norms and can be extended to other normative domains besides the law" [emphasis added P.C.].

${ }^{11}$ Cfr. http://www.w3.org/TR/2013/NOTE-rif-primer-20130205/ A productive rule assumes that if a certain condition holds, then some action is carried out (an instruction). E.g. "If a customer unduly delays
} 
the social sciences, norms have been often referred as having a social goal, such as the reduction of transaction costs in coordinated and collaborative situations. In philosophy, norms have been spelled out into different types of logics (descriptive, modal, deontic) following different analytical concepts referring to prescriptive natural language or to actions. In legal theory, the conception of norms is clearly connected with philosophical assumptions and, as contended, with an intuitive idea of the world constituents to be represented.

It is worthwhile to notice that isomorphism between rules of the legal system and their referred entities in the world (units of legal texts as documents, objects or behavior) has been often taken for granted. This is one of the most striking features of the representation of legal knowledge, as conceived and defended by computer scientists since practically the beginning of Artificial Intelligence \& Law: legal knowledge based systems are supposed to reflect the structure of their sources using (conceptual) intermediate representations (Bench-Capon and Coenen, 1992). Therefore, "as used in AI \& Law, isomorphism differs from standard mathematical usage" (Gordon and Bench-Capon, 2009). ${ }^{12}$

The analytical property which captures for any rule or norm the quality of belonging to a legal system is termed validity. 'Validity' [Geltung, gyldighed, gyldighet, validesa, validez, validità, validité] is one of the most discussed properties in legal theory -its "pineal gland" (Pattaro, 2007). ${ }^{13}$ A "valid" norm is a "legal norm". And, to acquire this quality of law, a rule or norm is expected to be (or become) valid. Analytical legal philosophers use to conceive this elusive property as (i) recursive (Alchourrón and Bulygin, 1974), (ii) supervenient (Hage, 2005), (iii) coordinative (Hart, 1961; Postema, 1982), and (iv) inferential (Sartor, 2007) -linked to the notion of inference stemming from legal concepts.

Not all four features need to be taken alike, and they can be fleshed out separately. But broadly speaking, this theoretical approach is in itself prescriptive, argumentationprone. The inferential role of the concept of validity "consists exactly in the fact that establishing that a norm is legally valid licenses us (and in fact obliges us, if the norm is relevant) to use the norm in legal reasoning" (Prakken and Sartor, 2013). The authors assume that norms are components of the system's knowledge base (not part of the argumentation system): isomorphism holds beforehand. Legal concepts are considered as directly generative of consequences, and, therefore, they can trigger normative legal reasoning and argumentations from this position in a logical way, avoiding unnecessary definitional criteria. ${ }^{14}$ The whole notion of 'legality' is considered a semantic prius.

This trend is not negligible, as it has quite positive effects. Deontic and defeasible logic have proved to be helpful in coping with the regulatory needs of the Semantic Web,

the payment, then he will be considered a defaulter and he can be sued". Alternatively, a declarative rule is thought as stating a fact about the world and is understood of having the form it has the form "if $\mathrm{P}$, then Q"; e.g. "If a person is born in Madrid, then he is Spanish". Declarative rules do not specify an action that is to be carried out.

${ }_{12}$ Cfr. Bench-Capon (1991), Prakken (1992), Sartor (1995), Gordon and Bench-Capon (2009).

${ }^{13}$ Cfr. nuances and some differences in Bulygin (1991a, 1991b), Sartor (2007, 2009), Alexy (1997, 2006). The best available account, in Grabowski (2014).

${ }^{14}$ The assumption is that especially non-monotonic logic, defeasible reasoning (not based on epistemic truth) and the analysis of non-inferential reasoning (e.g. analogy) can provide theoretical foundations for AI \& Law. See Prakken (1997). 
especially within linked open data contexts. Contracts, licenses, patents, and many other traditional legal acts can be reshaped and modeled into formal consistent patterns to ease their applicability and make them effective in the new Web 3.0 environment (Governatori, 2005; Governatori et al. 2013; Athan et al. 2013).

Therefore, a first type of theoretical models can be set encompassing almost exclusively the formal properties of deontic and legal systems, using RDF and RuleML. I will call them normative-Semantic Web Regulatory Models (n-SWRM). In these models, computer versions of rights, duties and obligations lean on the use and reuse of structured content. ${ }^{15}$ Examples can be taken from Digital Rights Management (DRM) and Rights Expression Language (REL), machine-processable languages used to express copyright or licenses as data and, quite often, as metadata to be searched, tracked or managed. E.g. Creative Commons is a well known example for using REL to express their licenses. The Open Digital Rights Language (ODRL) initiative constitutes another example. ODRL2.0 is now a W3C Community Group, developing it as a policy language. A common vocabulary is defined - e.g. actions, constraints, operators, and scopes-, XML encoding specifies the serialization of the Core Model in XML, and RDF encoding specifies the serialization of the Core Model in W3C SW languages. "The ODRL Core Model is designed to be independent from implementation mechanisms [highlighted PC] and is focused on the optimal model and semantics to represent policy-based information". ${ }^{16}$

In n-SWRM, logic is used to model a general interface with end-users in a plurality of general scenarios. Advanced deontic logic can be used to model reasoning about the normative semantics of permissions, prohibitions, duties and rights. Eg. Governatori et al. (2013) propose an extension of standard defeasible logic to set a composite license for Linked Open Data coming from heterogeneous distributed sources. The legal statuses of rights are considered 'facts' in the world, and reasoning is applied too on ontologies involved in different types of licenses (previously aligned). Grossi and Jones (2013. p. 424) note that "count-us allows for "defeasible institutional detachment". The inference from $\mathrm{X}$ to $\mathrm{Y}$ via "X counts as $\mathrm{Y}$ in context $\mathrm{C}$ " need not be logically valid as it can be retracted in the presence of further information. But do notice that what such an analysis need to assume is that it is legally valid.

\section{I-SEMANTIC WEB REGULATORY MODELS}

The relevance of methodology depends upon the specific problems to be solved. This is a matter of scale: in information processing situated environments, in local environments, where daily negotiation and interface between organizations take place, logic must be combined with other approaches as well. In this sense, non-normative intuitions can equally be considered, and a second conceptualization of SWRM comes into play.

I will use another term to denote the results of this second type of modeling: institutional-Semantic Web Regulatory Models (iSWRM), for what it is much more focused on institutional design, rather than on legal norms or legal systems. These

\footnotetext{
${ }^{15}$ E.g. 'Licensing' is defined by Renato Iannella as "the act of transferring limited rights to another party, under certain terms and conditions, for use and reuse of content" (Iannella, 2010).

${ }^{16}$ http://www.w3.org/community/odrl/two/model/
} 
models are not different in nature from nSWRM. Both fit into the social intelligence and the social machine perspectives, according to which "'programming the social computer' must be achievable from within the social computer - the methods of Web Science should output policy for governments and large organisations, but will also democratise control by allowing people to develop social machines to achieve their own smaller-scale, local, idiosyncratic purposes" (O'Hara et al. 2012, p. 110 and ff.).

I-SWRM face the tasks of designing regulatory systems for platforms and web services, ruling semantic web applications, building electronic institutions, or Normative Multiagents Systems (nMas) for specific purposes in specific settings. ${ }^{17}$ These tasks entail different epistemological and ontological commitments and different types of technical designs. But they all share the need of using norms, rules, guidelines and principles as building blocks and computerized devices. E.g. the implementation of nMAS requires five essential elements: a virtual space, a shared ontology, an interaction model, a set of regulations, and a governance model (Noriega et al. 2013, p. 96).

Implementing SW technologies to the law and embedding normative systems into artificial settings modifies what law has traditionally meant to human users. ${ }^{18}$ The classical conception of law as the exclusive domain of legal theory and jurisprudence falls short of providing such an expanded framework, ${ }^{19}$ for interaction poses its own problems and challenges to nMAS (Boella et al. 2008). ${ }^{20}$ Similarly, the notion of a "legal Semantic Web" cannot bridge by itself the gap between semantic languages and regulatory fields either, since the social implementation of complex regulatory systems requires a broader design. ${ }^{21}$ Consequently, some additional requirements to match SW technologies with legal ontologies and interchange languages are needed.

In i-SWRM, inner coordination among electronic agents, outer interface with human (collective) agents, and their dynamic interaction within different types of scenarios and real settings are key. They can be applied to regulatory systems with multiple normative sources and complex human-machine interactions between organizations, companies and administrations. Thus, their conceptual scheme is linked with legal pluralism and with existing models of asymmetric multi-layered and networked governance.

\footnotetext{
17 The consensual and standard definition of a nMAS is the following one: "a multiagent system organized by means of mechanisms to represent, communicate, distribute, detect, create, modify, and enforce norms, and mechanisms to deliberate about norms and detect norm violation and fulfillment." (Luck et al. 2005; Boella et al. 2008, p. 2). Cfr. about the use of electronic institutions, Mark d'Inverno et al. (2012), Fornara et al. (2013).

${ }^{18}$ In the same sense, see Pagallo $(2011,2013)$ on robotics: "focus should be on how information is created and distributed in a given network through the 'nodes', so that a system is complex when collective behaviour emerges from large webs of individual components with no central control or simple rules of operation" (Pagallo, 2012).

19 "Notice that we will not assume that the social perspective of norms be necessarily contrasted with the legal one. In fact, these two views are often taken to be symmetrically opposed: in the social paradigm norms fall within a bottom-up approach to normativity that is based on the concept of norm emergence; in the legal paradigm norms are mostly defined within a top-down, authority-based and institutionalised perspective.” (Blake et al. 2013, p. 2).

${ }^{20}$ A legalistic view of nMAS, where the normative system is considered "as a regulatory instrument to regulate emerging behavior of open systems without enforcing the desired behavior", opposes to an interactionist view, in which norms can be viewed "as regularities of behavior which emerge without any enforcement system.” (Boella et al., 2008, 3).

${ }^{21}$ Cfr. also Casanovas et al. (2010).
} 
Complex networks have at least a legal, a social, an organizational and a technological side. Therefore, interoperability is not only referred to languages but to organizations as well, for "interoperability of systems enables interoperability of organizations". ${ }^{22}$ This means that building institutions to rule, regulate or evaluate them - be they civil associations, companies, administrations or state agencies - should take into account the procedural processes linked to the actors at play. At scale, the micro-level effects of actors' behavior are relevant and cannot be ignored in the institutional design. Let's put an example.

\section{CAPER REGULATORY MODEL (CRM)}

The CAPER regulatory model (CRM) aims at managing police interoperability and protecting citizens' rights in the European space. It stems from the area of Freedom, Security and Justice, an overregulated domain that has long attracted the attention of legal and political actors. ${ }^{23}$

CAPER is a security platform to fight organized crime through the sharing, exploitation and analysis of open information sources. ${ }^{24}$ Its architecture is shown in Fig. $2{ }^{25}$ The main targets are: (i) information acquisition, processing, exploitation and standardisation; (ii) multilingual content analysis; (iii) integration with large scale systems, (iv) secure knowledge sharing and collaboration; (v) and legal and ethical issues.

\footnotetext{
22 "Systems interoperability is concerned with the ability of two or more systems or components to exchange information and to use the information that has been exchanged. Organizational interoperability is concerned with the ability of two or more units to provide services to and accept services from other units, and to use the services so exchanged to enable them to operate effectively together. Semantic interoperability is part of the interoperability challenge for networked organizations. Inter-organizational information systems only work when they communicate with other systems and interact with people". (Gottschalck, 2009)

${ }^{23}$ Cfr. Boehm, F. (2012) for a recent survey of EU legislation and Court rulings.

${ }^{24} \mathrm{http} / / / \mathrm{www} . \mathrm{fp} 7$-caper.eu/

${ }^{25}$ See Casanovas et al. (2014), González-Conejero et al. (2014).
} 


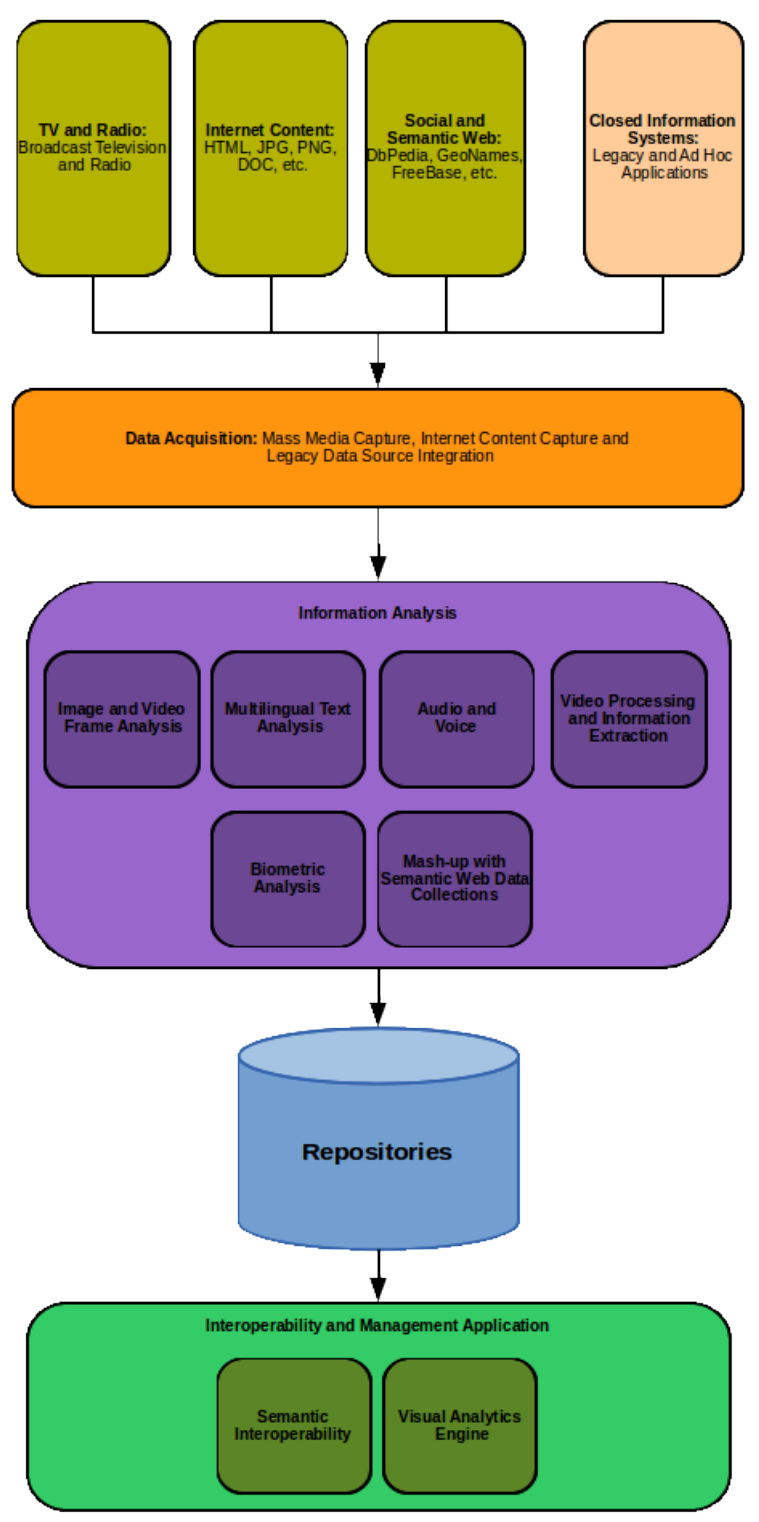

Fig. 2. CAPER architecture. Source: González-Conejero et al. (2014)

Several LEAs are testing the platform performance. ${ }^{26}$ But when they crawl the web searching for social information and they exchange it in specific investigations, they must follow several internal and external protocols. I.e. they have to be compliant not only with the normative systems contained into legal documentary sources -EU Directives, EU Regulations, national acts, and inner agency rules, among many othersbut with the principles, values and guidelines embedded in such systems, and with the ethical guidelines and recommendations set for the management of the platform. There are two ontologies taking care internally of this process —on legal concepts based on Interpol classification of crimes, and a multilingual ontology to perform the crawling of the web based on natural language and slang. ${ }^{27}$ However, the ontological work alone

\footnotetext{
${ }^{26}$ For a description of the research process and the results of the whole project, see Casanovas et al. (2014).

${ }^{27}$ For a description of the research process and the results of the whole project, see Casanovas et al. (2014). On legal crimes ontology building for LEAs interoperability , cfr. González-Conejero (2014).
} 
-i.e. singling out definitions of crime: a specific behavior under the same crime might be forbidden in UK but allowed in Spain- does not cover entirely the scope of controlling the investigative behavior within the platform (access, data harvesting, content processing, semantic storage and retrieval).

Caper Regulatory Model (CRM) is the conceptual mechanism underlying protocols and recommendations. It accounts for multilayered governance, cooperative behavior, and citizens' data protection. Fig. 1 plots the architecture of CRM. Dialogue with LEAs and security experts is crucial to understand where the problems are, and to let investigators participate into the regulatory process. But, at the same time, control is exerted because binding norms apply as well.

As Fig. 3 and 4 show, validity cannot be defined as a first order property: it depends on the two axes of binding power and social dialogue, and emerges as a property of a third axe, i.e. the institutional functioning of the whole system. Regulations unfold along an institutional continuum. Validity is a characteristic feature of such a continuum, a property pertaining and emerging from the whole regulatory system.

From this perspective, 'validity' can be conceptually defined as a second-order property, a four-tuple function of ethics (justice), policies (efficiency), soft law (effectiveness) and hard law (enforceability), fostering the application of metrics to measure institutional strengthening (i.e. the coordinated organization of components applying semantic technologies). The elements of the tuple cannot be directly assessed, for they are theoretical in nature. Nevertheless, they may be given different values to generate 'validity' as a composite indicator. Indicators can be ordered in a preference scale to evaluate the performance of tools and services, and thus determine their level of normative compliance. ${ }^{28}$

If this is the case, the ethical dimension of the whole regulatory system is at stake, because ethics does take a crucial constitutive role in i-SWRM, and, as it will be discussed in the next section, in n-SWRM as well. In the former, validity is a constituent of the model. In the later, validity can be reformulated through the interpretive work of the experts, as long as it is recognized that isomorphism between the content of legal databases and the intermediate representation of legal knowledge is not a neutral or completely automated process. "Shared knowledge" raises the additional problem of who defines and decide over the knowledge to be shared.

\footnotetext{
${ }^{28}$ That is to say, $V n \leq(J+E y+E s+E c)$, and $(J+E y+E s+E c) \Leftrightarrow V n$. This formulae still need some refinement, because a norm can be considered 'valid' only if the whole system counts as such. This means that 'validity' applies to the system, not to a single norm, which is considered 'valid' only indirectly. Metrics might come from the combination of the COBIT model, and the ISO/IEC 27001. Both have been already mapped. However, difficulties arise to measure the ethical component. Cfr. Ciambra and Casanovas (2014). For full-fledged legal composite indicators, see Vallbé (2014) and Vallbé and Casellas (2014)
} 


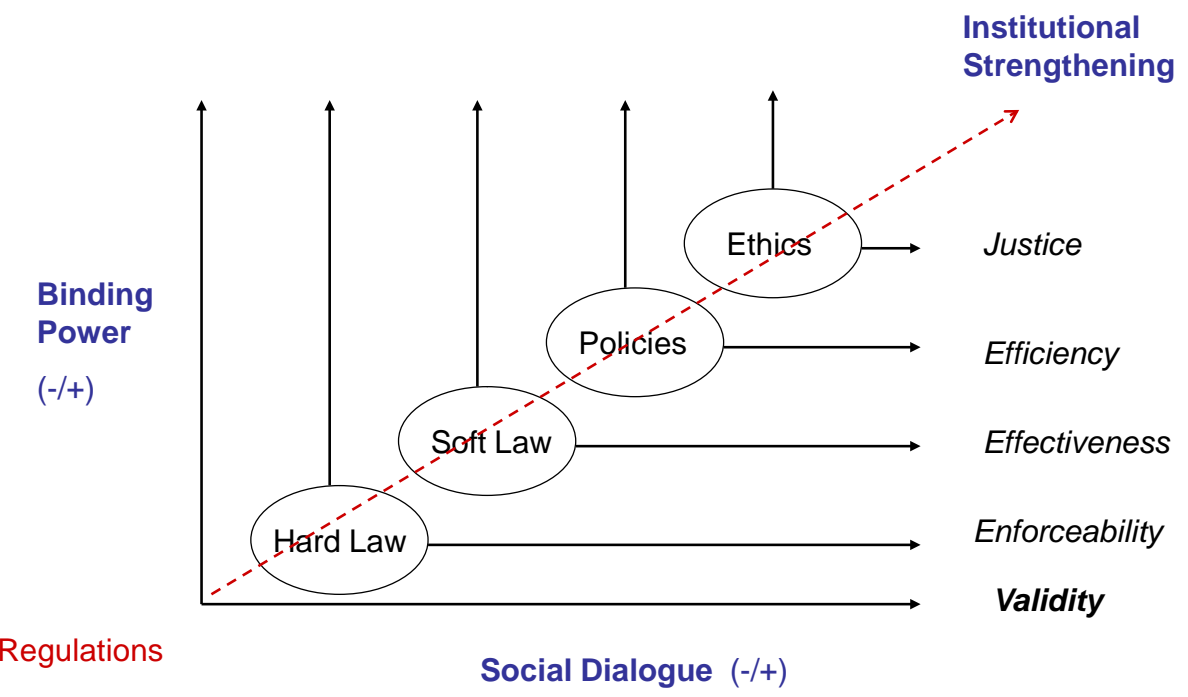

Continuum of legal institutional strengthening

Fig. 3. CAPER Regulatory Model (CRM)

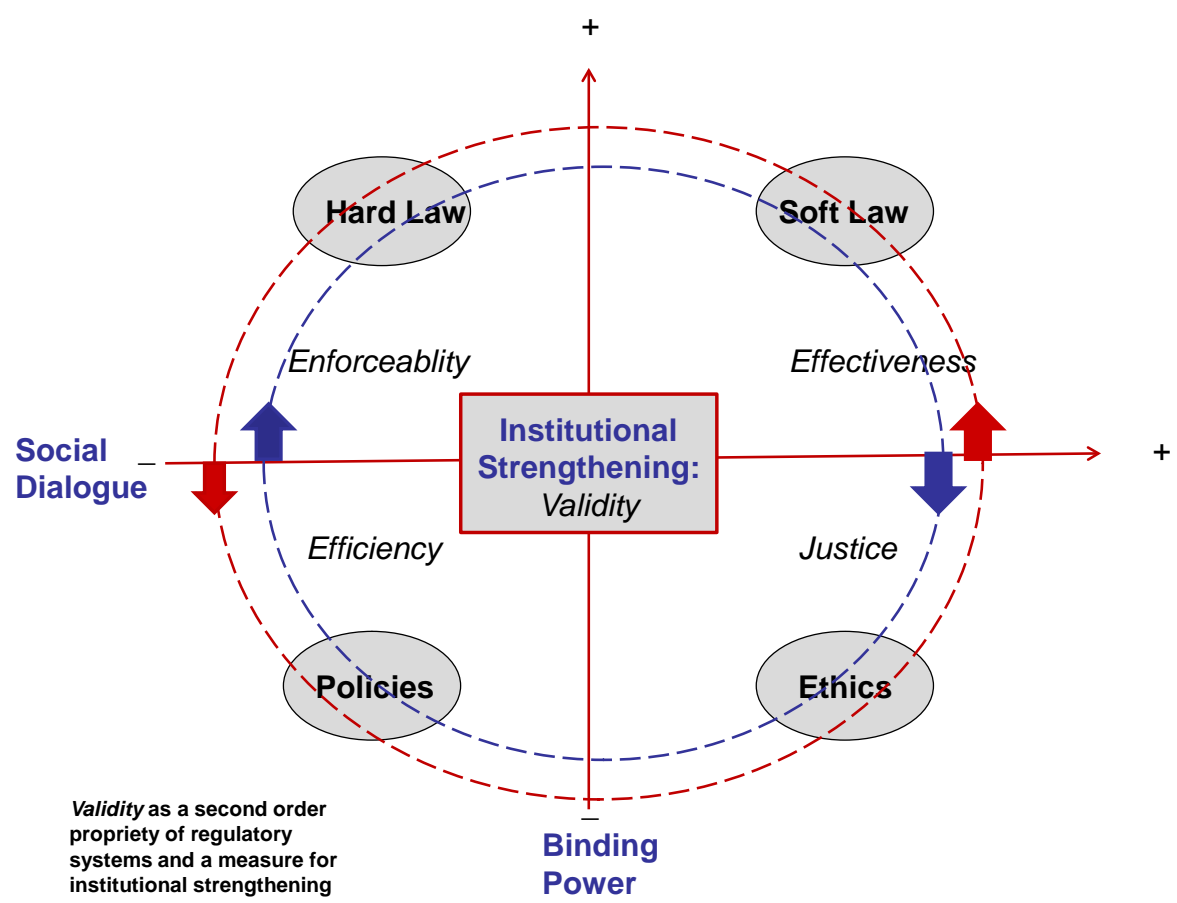

Fig. 4. Three axes, four first-order properties and one secondorder property for SWRM. 
In what it follows I will concentrate on the role of ethics. Let's deepen a bit more on principles of privacy, first. Table 1 summarizes the Principles of fair information practices (FIPs):

\begin{tabular}{|l|l|}
\hline $\begin{array}{l}\text { 1. Openness and } \\
\text { transparency }\end{array}$ & $\begin{array}{l}\text { There should be no secret record keeping. This includes both the publication of the } \\
\text { existence of such collections, as well as their contents. }\end{array}$ \\
\hline $\begin{array}{l}\text { 2. Individual } \\
\text { participation }\end{array}$ & The subject of a record should be able to see and correct the record. \\
\hline 3. Collection limitation & $\begin{array}{l}\text { Data collection should be proportional and not excessive compared to the purpose of } \\
\text { the collection. }\end{array}$ \\
\hline 4. Data quality & $\begin{array}{l}\text { Data should be relevant to the purposes for which they are collected and should be kept } \\
\text { up to date. }\end{array}$ \\
\hline 5. Use limitation & Data should only be used for their specific purpose by authorized personnel. \\
\hline 6. Reasonable security & $\begin{array}{l}\text { Adequate security safeguards should be put in place, according to the sensitivity of the } \\
\text { data collected. }\end{array}$ \\
\hline 7. Accountability & Record keepers must be accountable for compliance with the other principles. \\
\hline
\end{tabular}

Table 1. FIPs. Source: Langheinrich (2001).

These foundational principles have been embedded into EU Directives and regulations ${ }^{29}$, and have fostered academic, theoretical and practical discussions for the last ten years. The present disputes between the EU -including national states- and the US-based Web giants (Google, Twitter, Facebook, etc.) are well known. While the EU Data Protection framework seams to address conceptual privacy issues better than the US one, in practice it is hard to find any real-world Internet service implementing data protection by design conveniently and securely. ${ }^{30}$

In previous work, Ann Cavoukian has provided comparative tables on Privacy by Design Principles (Cavoukian 2006, 2010) ${ }^{31}$. In Table 2 below, I complete them with additional sets of principles for (i) Semantic Web Linked Open Data, (ii) Legal Information Institutes Principles, and (iii) Online Dispute Resolution (ODR).

\footnotetext{
${ }^{29}$ The notions of privacy by design and by default were eventually incorporated into the EU Document Digital Agenda for Europe (2010), which is the immediate precedent for the new regulations being put in place, Eu- COM/2012/010 final - 2012/0010 (COD. At present the EU Commission is still in the process of laying down the data protection system. Comments by de Hert and Papakonstantinou (2012, 130-31) still hold: "The stakes are high, because the Commission intends to replace nothing less than the entire EU data protection edifice. This herculean task shall be carried out by two instruments released simultaneously: the General Data Protection Regulation, intended to replace the EU Data Protection Directive 95/46/EC33 and the Police and Criminal Justice Data Protection Directive intended to replace the Framework Decision 2008/977/JHA.55 The latter has a short history and its replacement is perhaps more of a semantic rather than of substantial value. The replacement of the Directive, however, is an important and far-reaching development; once finalized, the new instrument is expected to affect the way Europeans work and live together."

30 See the devastating Report presented by Caspar Bowden in September 2013 to the European Parliament. Snowden's revelations about PRISM show that cyber mass-surveillance at the transnational level induces systemic breaches of fundamental rights. This also leads to question the scale of transnational mass surveillance and its implications for democracy.

31 Privacy by Design was adopted as an international privacy standard at the 32nd International Conference of Data Protection and Privacy Commissioners in Jerusalem. See Cavoukian (2012a, 2012b) for a quite complete overview.
} 
Semantic Web Linked Open Data (LOD) are the set of principles laid down by Tim Berners-Lee and James Hendler, among other members of the World Wide Web Consortium (W3C), for publishing data on the Web in a way that "all published data becomes a part of a single global space" (Bizer et al. 2009). The first set of principles (Berners-Lee, 2006) included the follow (amended later on): (i) Use URIs as names for things, (ii) use HTTP URIs so that people can look up thse names, (iii) when someone looks up a URI, provide useful information, using the standards (RDF, SPARQL), (iv) include links to other URIs, so that they can discover more things.

Legal Information Institutes Principles (LIIP) are the set of principles for the guidance of the World Legal Information Institutes (WLII) ${ }^{32}$ and the Free Access to Law Movement (FALM). FALM Declaration on Free Access to Law "takes the view that its members republish legal information (for free access by users) as a matter of right, not because of some largesse of governments" (Greensleaf et al., 2012, 6).

Online Dispute Resolution Principles (ODRP) are still under discussion. There is a tension between the Model Law (1985-2006) and the UNCITRAL (UNO) Arbitration Rules and the EU Data Protection Principles. ${ }^{33}$ One of the most influential reflections on fairness has been released by Lodder and Zeleznikow (2010).

I have selected these three fields because of their bottom-up moral impulse and their relationship with law, civil society, justice, and the market. Besides, it is easy to show their connection with data. E.g. It is a common place by now that e-Bay alone handles about 60 million disputes per year (Rule and Rogers, 2011).

\begin{tabular}{|c|c|c|c|c|c|}
\hline $\begin{array}{l}\text { Privacy by } \\
\text { Design } \\
\text { Foundational } \\
\text { Principles } \\
\text { [Cameron- }^{34} \\
\text { Cavoukian] }^{34} \\
\end{array}$ & $\begin{array}{l}\text { Fair Information } \\
\text { Practice } \\
\text { Principles (GPS) } \\
\text { [Cavoukian] }\end{array}$ & $\begin{array}{l}\text { Extended } \\
\text { Principles } \\
\text { [Cavoukian] }\end{array}$ & $\begin{array}{l}\text { Semantic Web } \\
\text { LOD Principles } \\
\text { [Berners-Lee - }^{\text {Hendler] }}{ }^{35}\end{array}$ & $\begin{array}{l}\text { Legal Information } \\
\text { Institutes } \\
\text { Principles } \\
\text { [Greenleaf- }_{\text {Bruce] }^{36}}\end{array}$ & $\begin{array}{l}\text { ODR Principles } \\
\text { [Lodder, } \\
\text { Zeleznikow, } \\
\text { Bellucci] }^{37}\end{array}$ \\
\hline $\begin{array}{l}\text { 1. Proactive not } \\
\text { reactive; } \\
\text { Preventative } \\
\text { not } \\
\text { Remedia }\end{array}$ & & $\begin{array}{l}\text { Demonstrable } \\
\text { commitment to } \\
\text { set and enforce } \\
\text { high privacy } \\
\text { standards. } \\
\text { Evidence that } \\
\text { methods to } \\
\text { recognize poor } \\
\text { privacy designs, } \\
\text { to anticipate poor } \\
\text { privacy practices } \\
\text { and outcomes, } \\
\text { and to correct the } \\
\text { negative impacts } \\
\text { proactively are } \\
\text { established. }\end{array}$ & $\begin{array}{l}\text { URIs to denote } \\
\text { things, HTTP } \\
\text { Dereferencing } \\
\text { Serialization formats } \\
\text { Proactive modeling: } \\
\text { XML, RDF, } \\
\text { SPARQL, OWL } \\
\text { Interconnectedness }\end{array}$ & $\begin{array}{l}\text { Technological } \\
\text { investment } \\
\text { Ensure republication } \\
\text { All primary legal } \\
\text { materials, and } \\
\text { publically funded } \\
\text { secondary ones }\end{array}$ & $\begin{array}{l}\text { Willingness to } \\
\text { enter into } \\
\text { negotiation }\end{array}$ \\
\hline
\end{tabular}

\footnotetext{
32 See http://www.worldlii.org/

${ }^{33}$ See the works by the UNCITRAL III Working Group, trying to harmonize the principles, http://www.uncitral.org/uncitral/commission/working_groups/3Online_Dispute_Resolution.html ${ }^{34}$ Cameron (2005), Cavoukian (2006, 2010, 2012a, 2012b), Cavoukian and Jonas (2012)

${ }^{35}$ Berners-Lee (2006, 2007, 2009), Berners-Lee, Hendler et al. (2010)

${ }^{36}$ Greenleaf (2009); Greenleaf, Mowbray, Chung (2012); Greenleaf and Bond (2012); Bruce and Hillmann (2004), Bruce (2009)

${ }^{37}$ Zeleznikow (2010, 2011a, 2011b); Zeleznikow and Bellucci (2012); Lodder and Zeleznikow (2012),

Abrahams, Bellucci, Zeleznikow (2012).
} 


\begin{tabular}{|c|c|c|c|c|c|}
\hline $\begin{array}{l}\text { 2. Privacy as the } \\
\text { Default } \\
\text { Setting }\end{array}$ & $\begin{array}{l}\text { 3. Purpose } \\
\text { Specification } \\
\text { 4. Collection } \\
\text { Limitation, } \\
\text { Data } \\
\text { Minimization } \\
\text { 5. Use, Retention } \\
\text { and Disclosure } \\
\text { Limitation }\end{array}$ & $\begin{array}{l}\text { Privacy as the } \\
\text { default starting } \\
\text { point for } \\
\text { designing and } \\
\text { operating } \\
\text { Information } \\
\text { Technologies and } \\
\text { systems represent } \\
\text { the maximum } \\
\text { personal privacy } \\
\text { that one can have. } \\
\text { That is, privacy } \\
\text { becomes the } \\
\text { prevailing } \\
\text { condition - } \\
\text { without the data } \\
\text { subject ever } \\
\text { having to ask for } \\
\text { it -no action } \\
\text { required. }\end{array}$ & $\begin{array}{l}\text { Dereferencing } \\
\text { Accessibility, Secure } \\
\text { data exchange, } \\
\text { protection, Storage, } \\
\text { Metadata, } \\
\text { Ontologies, Alarm } \\
\text { Systems, Trust }\end{array}$ & $\begin{array}{l}\text { Republication, } \\
\text { No copyright on } \\
\text { primary materials } \\
\text { No fees for } \\
\text { provision to } \\
\text { Republishers } \\
\text { Use open formats } \\
\text { and provide } \\
\text { metadata } \\
\text { Anonymization }\end{array}$ & $\begin{array}{l}\text { Fairness- } \\
\text { Enabling } \\
\text { Discovery } \\
\text { (Disclosure } \\
\text { Limitation) }\end{array}$ \\
\hline $\begin{array}{l}\text { 3. Privacy } \\
\text { Embedded } \\
\text { into Design }\end{array}$ & & $\begin{array}{l}\text { Systemic } \\
\text { program or } \\
\text { methodology in } \\
\text { place to ensure } \\
\text { that privacy is } \\
\text { thoroughly } \\
\text { integrated into } \\
\text { operations. It } \\
\text { should be } \\
\text { standards-based } \\
\text { and amenable to } \\
\text { review and } \\
\text { validation All } \\
\text { privacy threats } \\
\text { and risks should } \\
\text { be identified and } \\
\text { mitigated to the } \\
\text { fullest extent } \\
\text { possible in a } \\
\text { documented } \\
\text { action plan. } \\
\text { Trust }\end{array}$ & $\begin{array}{l}\text { Dereferencing } \\
\text { Looking up data, } \\
\text { structured data, Data } \\
\text { protection, Storage, } \\
\text { Metadata, } \\
\text { Enrichment, Core } \\
\text { Ontologies, Domain } \\
\text { Ontologies, Rules, } \\
\text { Principles, Trust, } \\
\text { Validation }\end{array}$ & $\begin{array}{l}\text { Republication } \\
\text { Reusing } \\
\text { Authentication } \\
\text { (Authoritative } \\
\text { versions) } \\
\text { Integrity }\end{array}$ & $\begin{array}{l}\text { Fairness- } \\
\text { Bargaining in the } \\
\text { shadow of the } \\
\text { law and the use } \\
\text { of BATNAs } \\
\text { Trust }\end{array}$ \\
\hline $\begin{array}{l}\text { 4. Full } \\
\text { Functionality - } \\
\text { Positive-Sum, } \\
\text { Not Zero-Sum }\end{array}$ & & $\begin{array}{l}\text { All legitimate } \\
\text { non-privacy } \\
\text { interests and } \\
\text { objectives are } \\
\text { identified early, } \\
\text { desired functions } \\
\text { articulated, } \\
\text { agreed metrics } \\
\text { applied, and } \\
\text { unnecessary } \\
\text { trade-offs } \\
\text { rejected in favor } \\
\text { of achieving } \\
\text { multi-functional } \\
\text { solutions. }\end{array}$ & $\begin{array}{l}\text { Web Science, } \\
\text { Universality, Linked } \\
\text { Data, Human Giant } \\
\text { Graph, } \\
\text { Accessibility, Data } \\
\text { protection, } \\
\text { Metadata, Core } \\
\text { Ontologies, Domain } \\
\text { Ontologies, Rules, } \\
\text { Principles, Trust, } \\
\text { Validation, }\end{array}$ & $\begin{array}{l}\text { Balanced } \\
\text { interests } \\
\text { (publisher/state/user) }\end{array}$ & $\begin{array}{l}\text { Fairness- } \\
\text { Enabling } \\
\text { Discovery } \\
\text { (Privacy } \\
\text { Limitation) }\end{array}$ \\
\hline $\begin{array}{l}\text { 5. End-to-End } \\
\text { Security } \\
\text { Full Lifecycle } \\
\text { Protection }\end{array}$ & 7. Security & & $\begin{array}{l}\text { Secure user } \\
\text { participation, } \\
\text { Ontology } \\
\text { sustainability, } \\
\text { folksonomies, }\end{array}$ & $\begin{array}{l}\text { Integrity, Security, } \\
\text { Maintenance }\end{array}$ & $\begin{array}{l}\text { Secure } \\
\text { environment }\end{array}$ \\
\hline $\begin{array}{l}\text { 6. Visibility and } \\
\text { Transparency - } \\
\text { Keep It Open }\end{array}$ & $\begin{array}{l}\text { 2. Accountability } \\
\text { 8. Openness } \\
\text { 10. Compliance }\end{array}$ & & $\begin{array}{l}\text { Transparency } \\
\text { Accountability } \\
\text { Content value, } \\
\text { tagging and semantic } \\
\text { enrichment }\end{array}$ & $\begin{array}{l}\text { Accountability, } \\
\text { Distributed } \\
\text { Authority of } \\
\text { republished } \\
\text { materials }\end{array}$ & $\begin{array}{l}\text { Developing } \\
\text { transparency }\end{array}$ \\
\hline $\begin{array}{l}\text { 7. Respect for } \\
\text { User Privacy - } \\
\text { Keep it User- } \\
\text { Centric } \\
\end{array}$ & $\begin{array}{l}\text { 1. Consent } \\
\text { 6. Accuracy } \\
\text { 9. Access }\end{array}$ & & $\begin{array}{l}\text { Personalization. } \\
\text { End user-centered } \\
\text { systems }\end{array}$ & $\begin{array}{l}\text { Consent, Integrity, } \\
\text { Content and added } \\
\text { value preservation }\end{array}$ & $\begin{array}{l}\text { Voluntarily } \\
\text { participation }\end{array}$ \\
\hline
\end{tabular}


Table 2. Comparison between FIPs, PbD, LOD, LII and ODR principles

There is a striking coincidence on objectives, structure and number of principles, since Chief Identity Architect of Microsoft Kim Cameron (2005) formulated the seven "laws of identity" from a purely computational point of view. ${ }^{38}$ It is out of the scope of this paper to address systematically their differences and similarities. For my purposes, what is worthwhile to highlight is that the main focus of the discourse lies on a deeper level, disclosing the ethical ground on which principles are based, and showing simultaneously the pragmatic trend of each approach.

Cameron's statements intended to be a technical formulation for an identity layer, a set of architectural notions: "the set of objective dynamics defining a digital identity metasystem capable of being widely enough accepted that it can serve as a backplane for distributed computing on an Internet scale". ${ }^{39}$ Contextual identity choices browsing, personal, professional, community, credit card, citizen- are, in their original formula, ways to make computable at the data level all the different contextual aspects that can shift from one to another environment. It is a way to codify user's interrelated interfaces within changing scenarios. On the contrary, Cavoukian's principles are normative, a golden standard proposal, a set of guidelines to be understood as a schema for evaluative and audit purposes that aims at guiding law and ethical judgments.

The different formulations contained in Table 2 point at different dimensions of the intersection between web 2.0 and Web 3.0. "The Social Web is an ecosystem of participation, where value is created by the aggregation of many individual user contributions. The Semantic Web is an ecosystem of data, where value is created by the integration of structured data from many sources" (Gruber, 2008). The emergence of patterns, norms and values does not occur in an abstract vacuum, but in a cross-fertilized content digital space which is essentially collective, tagged and structured by literally billions of semantic triples. The semantic layer is still a rather unknown dimension of the Internet (Berners-Lee et al. 2010).

38 The "seven laws" set by Cameron embrace: (i) User control and consent; (ii) Minimal disclosure for a constrained use (the solution which discloses the least amount of identifying information and best limits its use is the most stable long term solution); (iii) Justifiable parties (digital identity systems must be designed so the disclosure of identifying information is limited to parties having a necessary and justifiable place in a given identity relationship); (iv) Directed identity (a universal identity system must support both "omni-directional” identifiers for use by public entities and "unidirectional" identifiers for use by private entities, thus facilitating discovery while preventing unnecessary release of correlation handles); (v) Pluralism of operators and technologies (a universal identity system must channel and enable the inter-working of multiple identity technologies run by multiple identity providers; (vi) Human integration (the universal identity metasystem must define the human user to be a component of the distributed system integrated through unambiguous human-machine communication mechanisms offering protection against identity attacks); (vii) Consistent experience across contexts (the unifying identity metasystem must guarantee its users a simple, consistent experience while enabling separation of contexts through multiple operators and technologies). See, on the metasystem layer from a legal point of view, Lessig (2006).

39 "This investigation has led to a set of ideas called the "Laws of Identity". We chose the word "laws" in the scientific sense of hypotheses about the world - resulting from observation - which can be tested and are thus disprovable. The reader should bear in mind that we specifically did not want to denote legal or moral precepts, nor embark on a discussion of the 'philosophy of identity'”. Cameron, ibid. 4/11/2005. 
Data is not brute data nor institutionalized data: design offers many different possibilities in which data occurs and might be stored, stewarded, handled and managed by means of a specific set of tools and practices that are already known as data governance. Ontologies and SWRM are key among these new regulatory tools helping to maintain a balance between privacy and security. And neither ontologies nor SWRM (and their formal, hybrid or evaluative facets) are neutral. An ontology is a product of design.

Privacy by Design (and Privacy by Default) principles tend to stress the inner or private dimension of rights: respect for user privacy and informed consent. Linked Open Data principles, while defending the private side of data, highlight the accountability of the protocols settled on data use and reuse by companies, administrations and governments. Dereferenceable URIs (which obtain a copy or representation of the resource it identifies) are a precondition of the whole process. The recent principles lied down by Legal Information Institutes to rule the free reproduction and dissemination of legal content are focused on the republication of targeted legal materials (and no-copyright on primary materials). These focuses have their counterpart - consent/ publicity; accountability/ public security; republication/ intellectual property - in a nonhomogeneous continuum of rights and duties. $\mathrm{PbD}$ principles are user-centered, LOD's are data/protocol-centered, LIIP are platform or service-centered, ODR principles are process-centered.

This leads to a different definition of the private-public space continuum, in which rights and duties to be complied with are almost the same (as showed by the similarity of principles) but have different weight. Therefore, public consciousness, public space, public domain, and public agreement space can be distinguished, stemming from the different models of relational law that principles allow, and the different kind of citizens' rights than can be put in place (civil rights, global rights, added-value rights, procedural rights).

Distinguishing a global space from public domain is important here. Global space refers to the interactive relationships made possible by Web 2.0 and the upcoming Web 3.0. A global world, "one single giant graph", to use Berners-Lee metaphor, the field in which interactions, conflicts, negotiations on rights and duties take place. Public domain is a legal term, the regulation of rights going to commons under certain conditions set by Creative Commons or Open Data Commons licenses e.g., as a result of applying certain rules. It is my contention that legal devices, as shaped by SWRM, are apt enough to intermediate private, commercial and political relations on the Web. But only their ethical dimension can deal with the constitutive coordination of the global space. (This is why I cannot agree with a legal turn to be applied to the WWW or ideas about the "legal constitution" of the Internet: by definition, if it is legal, it cannot be global).

\section{VALIDITY IN THE LOOP}

Luciano Floridi (2004: 564) has mentioned the "data grounding problem", "intrinsic meaning", "intentionality", as one of the epistemic problems to be tackled by the philosophy of information. How can data acquire its meaning? How can the semantic interpretation of a formal symbol system be made intrinsic to the system? 
The problem is particularly acute with the upcoming Internet of (Linked) Services, which brings upon Web Services, Web 2.0, Semantic Web, the Web of Data, and Semantic Web Services (Pedrinaci and Domingue, 2010), especially because "best practices and norms on the Web are indeed largely not (yet) being made explicit", and many de facto standards do not emerge from standardization bodies, but from grass root efforts (Polleres, 2013). The Web has an aggregated nature.

SWRM constitute an attempt to add some rationale grounds to this diversity, among many others. Actually each layer of the SW stack generates, and will generate in the next future, many different standards; and ontologies have a regulatory side by themselves (especially those which are contextually-based). ${ }^{40}$

Formal SWRM, based on XML, RuleML and RDF, and SWRM fulfill some preconditions that are linked to the terms of the problem being solved. Validity is a result of this pre-conditional commitment.

In the next stages of the web, law is becoming relational ${ }^{41}$, a situation in which links between texts (in big repositories) and their end users (be they officers or lay people) comes through complex social systems mediated by computer languages and digital objects. Law becomes not only interpreted, but stored, dereferenced, retrieved, crowdsourced, and used within social, economic and institutional networks where regulations take place through complex patterns of behavior, beyond the single individual's end point. We are just beginning to understand the inner organization and shape of legal linked data, operating through automated ontologies (Hoekstra, 2013). An ontology has not to be "true", but useful, sustainable, and reusable. To be durable, it has to reflect reasonably the knowledge of a certain domain. A design pattern is a methodological device, a template, to structure and manage some recurrent features of such a knowledge. "An ontology design pattern [ODP] is a reusable successful solution to a recurrent modeling problem." 42

The only proposed ODP in the legal domain is LicenseLinkedDataResources, to provide "a pattern for expressing rights on Linked Data Resources, understood as RDF triples, datasets or mappings. These rights include intellectual property rights, database rights and the right of access, which can be limited by personal data protection laws and others. Rights expressions may assert, waive and license the rights, either conditionally or inconditionally, either to the public or to agents in particular." 43

Both ontologies and ODP can be understood as components of Semantic Web Regulatory Models, for they are technical instruments that do not "count as" immediately legal in the public or private domains. As stated, the global space cannot be confused with a private or public domain. Legal consequences do not follow from

\footnotetext{
${ }^{40}$ See the special edition by Lehman et al. (2012). E.g. OWL-based representation of policies with ontology consistency checking for distributed systems (Sensoy et al. 2012), and the interaction-based approach to semantic alignment (Atencia and Schorlemmer, 2012). On contextual ontologies, see the results of the EU NeON Project, http://www.neon-project.org .

${ }^{41}$ See Casanovas (2009, 2010, 20012a, 2012b, 2013); Casanovas and Poblet (2008).

42 http://ontologydesignpatterns.org/wiki/Odp:WhatIsAPattern See Gangemi (2005) on ODP.

43 http://ontologydesignpatterns.org/wiki/Submissions:ContentOPs Submitted by Víctor RodríguezDoncel, Mari Carmen Suárez-Figueroa, Asunción Gómez-Pérez and María Poveda (2013). See Rodríguez-Dncel et al. (2013).
} 
the use of ontologies or ODP, but they might follow from SWRM as they must necessarily consider, reckon and anticipate them.

But, both normative and institutional SWRM are necessary hybrid, according to the many organizations, jurisdictions and governments they come across. Even standard licenses like Creative Commons can be questioned or diversely interpreted in some jurisdictions, as it just happened with the recent decision of the Cologne Federal Court in Germany reversing the content and meaning of the fifth CC license. ${ }^{44}$

Therefore, SWRM count as tools of data governance. At least in i-SWRM, validity is not acting primarily as a property to single out whether norms are 'legal', but rather as a sub-product that stems sub-causally from the presence of other properties.

One interesting feature of such models comes from the fact that ethics appears to be one of their essential components. First, because ethics are properly ruling in several different ways —ethical issues are explicitly mandatory into the new European Directives and Regulations, ethical codes can be alleged before the Courts of Justice, Privacy and Data Protection Impact assessments are a prerequisite for the implementation of public policies in the area of Freedom, Security and Justice... But, most important, because ethics constitute an inescapable dimension of dialogue as a primary source of law or, as I prefer to say, of relational law, on the Web.

Broadly speaking, respect, consent, trust, accountability, republication, fairness and transparency (the main focuses of PbD, DPbD, LOD, LII and ODR) constitute the new dialogic fields of the multidimensional global space in which SWRM operate.

On the web, nMAS and artificial societies, the production of such a legal order - a means to produce compelling behavior- does not happen only in a top-down authority relation or as a product of standardization bodies, but it rather emerges as well from the interactive behavior among agents. Thus, centralized production of rules and norms are not as effective as reputation (Jøsang et al. 2007), ostracism (Perreau de Pinninck et al. 2008), trust and forms of transparency (Simon, 2010), or coordinated decentralized enforcement (Hadfield and Heingast, 2012).

\section{CONCLUSIONS}

In this article I have outlined a way to conceptually model from a descriptive approach some elements that refine and slightly modify the normative notion of law, stemming from its implementation in regulatory systems. I have contended that the validity of norms, rules and principles cannot be directly applied as an identification property to single out their legality. This means that there is a tension between the ideal or prescriptive dimension of regulations and the design of specific regulatory models, both in nMAS, or embedded into platforms and web services.

At least two conclusions can be drawn from this position:

44 Landgericht Köln, Urteil vom 5. März 2014 (Az.: 28 O 232/13): "Nach dem objektiven Erklärungswert ist unter der Bezeichnung "nicht kommerzielle Nutzung" eine rein private Nutzung zu verstehen". After the declaration, "non commercial use" can be understood as a purely private use, which it is not what the license intended to mean. 
1. SWRM, be they normative or institutional, are able to describe and redesign regulatory systems and their legal side, stemming from norms, rules, policies, best practices, and ethical principles and values.

2. A multidimensional global space emerges and should be broadly redefined according to the dialogical ethical guidelines of SWRM.

There are some limitations and conceptual problems as well. Crowdsourcing, crisis mapping, disaster management, corruption detection, raise regulatory problems by their own when large populations are involved (Poblet, 2011; Poblet et al. 2014). Applicable metrics to ethical issues are far from clear.

The difference between n-SWRM and i-SWRM, although useful for specific purposes, is a pragmatic and heuristic one. Perhaps a single theorization, coming from social intelligence modeling —artificial socio-cognitve technical systems (Andriguetto et al. 2013, Noriega et al. 2014)_, encompassing deontic schemes with legal conceptual schemes to manage compliance (Boella et al. 2014), or providing a general ontology for nMAS within the so-called Constructive Descriptions and Situations paradigm (CDS) (Gangemi, 2008) might offer a complementary (or even alternative) account of their structure, composition, and functioning. A systematic account of all different proposals is still to be done. But putting law, governance and ethics together at work within the AI, SW and nMAS fields constitute an unavoidable challenge for the respective communities.

AKNOWLEDGMENTS. CAPER, EU Grant Agreement 261712; CROWDSOURCING DER2012-39492-C02-0, SINTELNET FP7-ICT-2009-C-286380; CONSUMEDIA INNPACTO IPT-2011-1015-430000; CROWDCRISISCONTROL IPT-2012-0968390000. Pablo Noriega, Marta Poblet, Albert Meroño-Peñuelas and Massimo Durante read it and made useful comments on a previous manuscript. The criticism by an unknown reviewer made me think aloof and get some distance from my own formulation. Of course, the final responsibility for defaults and misunderstandings is only mine.

\section{REFERENCES $^{45}$}

Abrahams, B., Bellucci, E., Zeleznikow J. (2012). Incorporating Fairness into Development of an Integrated Multi-agent Online Dispute Resolution Environment. Group Decision and Negotiation 21, 3-28.

Alchourrón, C. \& Bulygin, E. (1974). Introducción a la metodología de las ciencias jurídicas y sociales. Buenos Aires: Editorial Astrea.

Alexy, R. (1997). El concepto y la validez del derecho (1992). Barcelona: Gedisa.

Alexy, R. (2006). A Theory of Constitutional Rights (1986). Oxford: Oxford University Press.

\footnotetext{
${ }^{45}$ All digital resources have been accessed for the last time in May 1st 2013.
} 
Andrighetto, G., Governatori, G., Noriega, P., van der Torre, L.V.N. (eds.) (2013). Normative Multi-Agent Systems, Schloss Dagstuhl - Leibniz-Zentrum für lnformatik GmbH , Dagstuhl Publishing, Saarbrücken/ Wadern, Gennany. Available online at http://www.dagstuhl.de/dagpub/978-3-939897-51-4

Atencia, M., Schorlemmer, M. (2012). An interaction-based approach to semantic alignment", Web Semantics: Science, Services and Agents on the World Wide Web 1213 (2012), 131-147.

Athan, T., Boley, H., Governatori, G., Palmirani, M., Paschke, A., Wyner, A. (2013). OASIS LegalRuleML , JURIX-2013, Bologna, Italy, December 11th-13th.

Balke, T., da Costa Pereira, Dignum, F., Lorini, E., Rotolo, A., Vasconcelos, W., Villata, S. (2013) Norms in MAS: Definitions and Related Concepts, in Normative Multi-Agent Systems, 1-32. http://www.dagstuhl.de/dagpub/978-3-939897-51-4

Bellucci, E., Lodder, A., Zeleznikow J. (2004). Integrating Artificial Intelligence, Argumentation and Game Theory To Develop an Online Dispute Resolution Environment, Proceedings of the 16th IEEE International Conference on Tools with Artificial Intelligence (ICTAI 2004), IEEE.

Bench-Capon, T.J.M., Coenen, F.P. (1992). Isomorphism and Legal Knowledge Based Systems, Artificial Intelligence and Law 1, (1992) 65-86.

Bench-Capon, T.J.M., Gordon, T.F. (2009). Isomorphism and Argumentation, ICAIL Proceedings, ACM, 11-20.

Berners-Lee, T. (2006). Linked Data (updated 2009), http://www.w3.org/DesignIssues/LinkedData.html

Berners-Lee, T. (2007). The Giant Global Graph, Wed, 2007-11-21, Semantic Web Technologies, http://dig.csail.mit.edu/breadcrumbs/node/215

Berners-Lee, T. (2009). Tim Berners-Lee on the next Web, TED Talk. http://www.ted.com/talks/tim_berners_lee_on_the_next_web.html

Berners-Lee, T., Hall, W., Hendler, J.A., O’Hara, K., Shadbolt, N., Weitzner, D.J. (2010) A Framework for Web Science, Foundations and Trends in Web Science (1) 1, $1-13$.

Bizer, C., Heath,T. Berners-Lee, T. (2009 ) Linked Data - The Story So Far. Heath, T., Hepp, M., and Bizer, C. (eds.). Special Issue on Linked Data, International Journal on Semantic Web and Information Systems (IJSWIS) 5, 3: 1-22.

Boehm, F. (2012). Information Sharing and Data Protection in the Area of Freedom, Security and Justice. Towards Harmonised Data Protection Principles for Information Exchange at EU-level, Dordrecht, Heidelberg: Springer Verlag. 
Boella, G., van der Torre, L., Verhagen, H. (2008). Ten challenges for normative multiagent systems, Dagstuhl Seminar Proceedings 08361, Programming Multi-Agent Systems, http://drops.dagstuhl.de/opus/volltexte/2008/1636

Boella, G., Tossato, S.C., Ghanavati, S., Hulsijgn, J., Humphreys, L., Muthuri, R., Rifaiut, A., van der Torre, L. (2014). Integrating Legal-URN and Eunomos: Towards a Comprehensive Compliance Management Solution. AICOL-SINTELNET Joint Workshop, Bologna, JURIX 13', 11 December (LNAI, Springer, forthcoming).

Bowden, C. (2013). The US surveillance programmes and their impact on EU citizens' fundamental rights, Presented to the European Parliament's Committee on Civil Liberties, Justice and Home Affairs (LIBE Committee) 5/09/2013, PE 474.405. http://www.europarl.europa.eu/meetdocs/2009_2014/documents/libe/dv/briefingnote_b riefingnote_en.pdf

Bruce, T.R. \& Hillmann, D. (2004). The Continuum of Metadata Quality: Defining, Expressing, Exploiting, Metadata in Practice, ALA Editions, available at LII Cornell: http://hdl.handle.net/1813/7895

Bruce, T.R. (2009), Foundings on the Cathedral Steps, in Peruginelli, G. and Ragona M. (Eds.), Law via the Internet. Free Access, Quality of Information, Effectiveness of Rights (pp. 411-422), Florence: European Press Academic Publishing.

Bulygin, E. (1991a). Tiempo y validez (1982), in C. Alchourrón y E. Bulygin, Análisis lógico y derecho (pp. 195-214), Madrid: Centro de Estudios Constitucionales.

Bulygin, E. (1991b). Validez y positivismo (1987, 1990), in C. Alchourrón y E. Bulygin, Análisis lógico y derecho (pp. 499-519), Madrid: Centro de Estudios Constitucionales.

Cameron, K. (2005). The Laws of Identity ... as of 5/11/2005. Microsoft Corporation, http://www.identityblog.com/stories/2005/05/13/TheLawsOfIdentity.pdf

Casanovas, P. (2012b). Legal Crowsourcing and Relational Law. What the Semantic Web Can Do for Legal Education, Journal of Australian Law Teachers Association (JALTA) 5 (1 \& 2), 159-176. Available at http://www.alta.edu.au/resources/PDFs/JALTA/Full\%20Volumes/2012_vol5_no1\&2.p $\underline{\mathrm{df}}$

Casanovas, P. \& Poblet, M. (2008). Concepts and fields of Relational Justice, in P. Casanovas, G. Sartor, N. Casellas, R. Rubino (Eds.), Computable Models of the Law. Languages, Dialogues, Games, Ontologies, LNAI 4884 (pp. 323-335), Heidelberg, Berlin: Springer Verlag.

Casanovas, P. (2009). The Future of Law: Relational Law and Next Generation of Web Services, in M. Fernández-Barrera, P. de Filippi, N. N. Andrade, M. Viola de Azevedo, G. Sartor, P. Casanovas (Eds.) The Future of Law and Technology: Looking into the Future.Selected Essays (pp. 137-156) Florence: European Press Academic Publishing. 
Casanovas, P. (2012a). Algunas líneas de investigación en gestión del conocimiento jurídico. Web semántica, ODR y derecho relacional. SCIRE. Representación y organización del conocimiento. 18 (1), 15-28.

Casanovas, P. (2013). Agreement and Relational Justice: A Perspective from Philosophy and Sociology of Law, Sascha Ossowski (Ed.) Agreement Technologies, LGTS n. 8 (pp. 19-42), Dordrecht, Heidelberg: Springer Verlag.

Casanovas, P., Pagallo, U., Sartor, G., Ajani, G.M. (2010). Introduction: Complex Systems and Six Challenges for the Development of Law and the Semantic Web, P. Casanovas et al. (Eds.), AI Approaches to the Complexity of Legal Systems-09, LNAI 6237 (pp. 1-11), Berlin, Heidelberg: Springer Verlag.

Casanovas, P., Arraiza, J., Melero, F., Tarrafeta, L. (Eds.) (2014). Crawling Open Source Intelligence. Collaborative Information, Acquisition, Processing, Exploitation and Reporting for the Prevention of Organised Crime. LGTS, Dordrecht, Berlin: Springer Verlag (forthcoming).

Cavoukian, A. \& Jonas, J. (2012). Privacy by Design in the Era of Big Data, June 8, http://privacybydesign.ca/content/uploads/2012/06/pbd-big_data.pdf

Cavoukian, A. (2006). 7 Laws of Identity: The Case For Privacy-Embedded Laws of Identity in the Digital Age, Technology (pp. 1-24), Ontario Information and Privacy Commissioner, October 2006.

Cavoukian, A. (2010). Privacy by Design. The 7 Foundational Principles. Implementation and Mapping of Fair information Practices. Information an Privacy Commissioner, Ontario, Canada. http://www.privacybydesign.ca/index.php/aboutpbd/7-foundational-principles/

Cavoukian, A. (2012a). Privacy by Design: Origins, Meaning, and Prospects for Assuring Privacy and Trust in the Information Era. NY: Igi Global. DOI: 10.4018/9781-61350-501-4.ch007.

Cavoukian, A. (2012b). Privacy by Design, IEEE Technology and Society Magazine, DOI 10.1109/MTS.2012.2225459, 18-19.

Ciambra, A., Casanovas, P. (2014). Drafting a composite indicator of validity for regulatory models and legal systems. AICOL-SINTELNET Joint Workshop, Bologna, JURIX 13', 11 December (LNAI, Springer, forthcoming).

D'Inverno, M., Luck, M., Noriega, P., Rodríguez-Aguilar, J.A., Sierra, C. (2012). Communicating Open Systems, Artificial Intelligence 186, 38-94.

De Hert, P, Papakonstantinou, V. (2012). The proposed data protection Regulation replacing Directive 95/46/EC: A sound system for the protection of individuals, Computer Law \& Security Review 28: 130-142.

Floridi L. (2006). The Ontological Interpretation of Informational Privacy, Ethics and Information Technology, 7(4), 185-200. 
Fornara, N., Lopes Cardoso, H., Noriega, P., Oliveira, E., Tampitsikas, Ch., Schumacher, M.I. (2013). Modelling Agent Institutions, Agreement Technologies. Law, Governance and Technology Series, no. 8 (pp. 277-307). Dordrecht, Heidelberg: Springer Verlag.

Gangemi, A. (2005). Ontology Semantic Web Patterns for Semantic Web Content. Y. Gil et al. (Eds.), ISWC 2005, LNCS 3729, pp. 262-276.

Gangemi, A. (2009). Norms and plans as unification criteria for social collectives. Journal of Autonomous Agents and Multi-Agent Systems (2008) 17:70-112, DOI 10.1007/s10458-008-9038-9

González-Conejero, J., Rebeca Varela-Figueroa, R., Muñoz-Gómez, J., Teodoro, E. (2014). Organized Crime Structure Modelling for European Law Enforcement Agencies Interoperability Through Ontologies, AICOL-SINTELNET Joint Workshop Bologna, JURIX 13', 11 December (LNAI, Springer, forthcoming).

Gordon,T.F., Governatori, G., Rotolo, N. (2009). Rules and Norms: Requirements for Rule Interchange Languages in the Legal Domain, in G. Governatori, J. Hall and A. Paschke (Eds.) Rule Representation, Interchange and Reasoning on the Web, RuleML, LNCS 5858 (pp. 282-296), Dordrecht, Heidelberg: Springer Verlag.

Gottschalk, P. (2009). Maturity levels for interoperability in digital government, Government Information Quarterly 26: 75-81.

Governatori, G. (2005). Representing Business Contracts in RuleML, International Journal of Cooperative Information Systems, 14 (2-3). DOI: 10.1142/S0218843005001092.

Governatori, G., Rotolo, A., Villata, S., Gandon, F. (2013). One License to Compose Them All: A Deontic Logic Approach to Data Licensing on the Web of Data, International Semantic Web Conference-ISWC 1, LNCS 8218 (pp. 151-166), Springer, Dordrecht, Heidelberg: Springer Verlag.

Grabowski, A. (2014). Juristic Concept of the Validity of Statutory Law. A Critique of Contemporary Legal Nonpositivism, Berlin, Dordrecht: Springer Verlag .

Greenleaf, G \& Bond, C. (2013). 'Public rights' in copyright: What makes up Australia’s public domain?, Australian Intellectual Property Journal 23, 111-138.

Greenleaf, G., Mowbray, A., Chung, P. (2012). The meaning of 'free access to legal information': A twenty year evolution. Law via Internet Conference 2012, Cornell University, Ithaca, USA, October. Available at http://papers.ssrn.com/sol3/papers.cfm?abstract_id=215886, published at Journal of \begin{tabular}{lllll}
\hline Open Access Law & (JOAL), & Issue & 1.
\end{tabular} http://ojs.law.cornell.edu/index.php/joal/article/view/11

Greenleaf, M. (2009). AustLII's Business Models: Constraints and Opportunities in Funding Free Access to Law, in Peruginelli, G. and Ragona M. (Eds.), Law via the 
Internet. Free Access, Quality of Information, Effectiveness of Rights (pp. 423-437), Florence: European Press Academic Publishing.

Grossi, D., Jones, A. (2013). Constitutive Norms and Counts-as Conditionals, in D. Gabbay, J.Horty, X.Parent, R.v.d. Meyden, L. v. d. Torre (Eds.) Handbook of Deontic Logic and Normative Systems (407-441). Milton Keynes UK: College Publications.

Gruber, T. (2008). Collective knowledge systems: Where the Social Web meets the Semantic Web, Web Semantics: Science, Services and Agents on the World Wide Web 6, 4-13.

Hadfield, G. K. \& Weingast B.R. (2012). What is law? A Coordination model of the Characteristics of Legal Order, Journal of Legal Analysis 4.2. doi:10.1093/jla/las008 http://works.bepress.com/ghadfield/36

Hage, J.C. (2005). Studies in Legal Logic. Dordrecht: Springer Verlag.

Hart, H. L. A. (1961/1997). The Concept of Law. 2nd edition. New York, Oxford: Oxford University Press.

Hendler, J.A. \& Berners-Lee, T. (2010). From the Semantic Web to social machines: A research challenge for AI on the World Wide Web, Artificial Intelligence 174, 156-161.

Hendler, J.A. (2009). Web 3.0 Emerging. Computer, IEEE Society, January, 88-90.

Herman, I. (2009). W3C Semantic Web Frequently Asked Questions. What is the Semantic Web? http://www.w3.org/RDF/FAQ.

Hoekstra, R. (2013). A Network Analysis of Dutch Regulations Using the MetaLex Document Server, JURIX-2003, Bologna December 11th-14th.

Iannella, R. (2010). Digital Rights Management Technology, H. Bidgoli (Ed.), Handbook for Technology Management, vol. III, chapter 62. London: Wiley. Available at NICTA http://www.nicta.com.au/pub?doc=764

Jøsang, A., Ismail, R., Boyd, C.A. (2007). A survey of trust and reputation systems for online service provision, Decision Support Systems 43(2), 618-644.

Langheinrich, M. (2001). Privacy by Design - Principles of Privacy-Aware Ubiquitous Systems, in Gregory D.A., Abowd, B. Brumitt, S.A. Shafer (Eds.), Proceeding UbiComp '01 Proceedings of the 3rd international conference on Ubiquitous Computing (pp. 273-291). London: Springer.

Lehmann, J., Varzinczak, I.J., Bundy, A. (2012). Reasoning with Context in the Semantic Web, Web Semantics: Science, Services and Agents on the World Wide Web 12-13, 1-2.

Lessig, L. (2006). Code. Version 2.0. New York: Basic Books. http://codev2.cc/ 
Lodder, A. \& Zeleznikow J. (2005). Developing an Online Dispute Resolution Environment: Dialogue Tools and Negotiation Systems in a Three Step Model, 10 The Harvard Negotiation Law Review, 287-338.

Lodder, A. \& Zeleznikow J. (2010). Enhanced Dispute Resolution Through the Use of Information Technology. Cambridge: Cambridge University Press.

Lodder, A. (2006). The Third Party and Beyond. An Analysis of the Different Parties, in particular The Fifth, Involved in Online Dispute Resolution, Information \& Communications Technology Law, 15 (2), June, 143-155.

Luck, M., McBurney, P., Shehory, O., Willmott (Eds.) (2005). Agent Technology: Computing as Interaction. A Roadmap for Agent Based Computing, http://www.agentlink.org/roadmap/al3rm.pdf

Noriega, P., Chopra A.K., Fornara, N., Lopes Cardoso, H.; Singh, M. (2013). Regulated MAS: Social Perspective, in Normative Multi-Agent Systems, pp. 93-134. Available at http://drops.dagstuhl.de/opus/volltexte/2013/4001/

Noriega, P., Padget, P., Verhagen, H., d’Inverno, M. (2014). The Challenge of Artificial Socio-Cognitive Systems, Available, AMMAS 14' Proceedings at: http://aamas2014.lip6.fr/proceedings/workshops/AAMAS2014-W22/p12.pdf.

O’Hara, K., Noshir S. Contractor, N.S., Hall, W., Hendler, J.A., Shadbolt, N. (2012). Foundations and Trends in Web Science, 4, 2-3 (2012) 103-267.

Ossowksi, S. (Ed.) (2013). Agreement Technologies, LGTS n. 8, Dordrecht, Heidelberg: Springer Verlag.

Pagallo, U. (2012). Three Roads to Complexity, AI \& the Law of Robots: On Crimes, Contracts, and Torts. M. Palmirani, U. Pagallo, P. Casanovas, G. Sartor (Eds), AI Approaches to the Complexity of Legal Systems. Models and Ethical Challenges for Legal Systems, Legal Language and Legal Ontologies, Argumentation and Software Agents (pp 48-60), LNAI 7639, Heidelberg: Springer Verlag.

Pagallo, U. (2013). The Law of Robots. Crimes, Contracts, and Torts, LGTS n. 10, Dordrecht, Heidelberg: Springer Verlag.

Pattaro, E. (2007). The Law and the Right. A Reappraisal of the Reality that Ought to Be. A Treatise of Legal Philosophy and General Jurisprudence, vol. 1. Dordrecht: Springer Verlag.

Pedrinaci, C. \& Domingue, J. (2010). Toward the Next Wave of Services: Linked Services for the Web of Data, Journal of Universal Computer Science, 16 (13), 16941719.

Perreau de Pinninck, A., Sierra, C., Schorlemmer, M. (2008). Distributed Norm Enforcement: Ostracism in Open Multi-Agent Systems, in G. Sartor, P. Casanovas, N. Casellas, R. Rubino (Eds.) Computable Models of the Law, Languages, Dialogues, Games, Ontologies, LNAI 4884 (pp. 275-290), Heidelberg: Springer Verlag. 
Poblet, M. (Ed.) (2011). Mobile Technologies for Conflict Management: Online Dispute Resolution, Governance, Participation, LGTS, Dordrecht, Heidelberg: Springer Verlag.

Poblet, M., Noriega, P., Plaza, E. (Eds.) (2014). Crowd 2014: Crowdintelligence: Foundations, Methods and Practices. Proceedings of the Sintelnet WG5 Workshop on Crowd Intelligence: Foundations, Methods, and Practices. Barcelona, 8-9 January CEUR Workshops Proceedings, vol. 1148.

Polleres, A. (2013). Agreement Technologies and the Semantic Web, in S. Ossowski (ed.) Agreement Technologies, LGTS n. 8 (pp. 57-67), Dordrecht, Heidelberg: Springer Verlag.

Postema, G.. (1982). Coordination and Convention at the Foundations of Law, Journal of Legal Studies 11, 165-203.

Prakken, H. (1997). Logical Tools for Modelling Legal Argument. A Study of Defeasible Reasoning in Law. Dordrecht: Kluwer Academic Publishers.

Prakken, H., Schrickx J. (1991) Isomorphic Models for Rules and Exceptions in Legislation. in J.A.P.J. Breuker, R.V. De Mulder, J.C. Hage (Eds.) Legal knowledge based systems. Model-based legal reasoning. JURIX 91, 17-27.

Rodríguez-Doncel, V., Suárez-Figueroa, M.C., Gómez-Pérez, A., Poveda, M. (2013). LicenseLinkedDataResources, http://ontologydesignpatterns.org/wiki/Submissions:ContentOPs

Rodríguez-Doncel, V., Gómez-Pérez, Mihindukulasooriya, N. (2013) Rights declaration in Linked Data, O. Hartig, J. Sequeda, A. Hogan, T. Matsutsuka (Eds.), Proceedings of the Fourth International Workshop on Consuming Linked Data, COLD 2013, Sydney, Australia, October 22, CEUR-WS.org 2013 CEUR Workshop Proceedings, pp. 1-12.

Rule, C.; Rogers, V. (2011). Building a Global System for Resolving High-Volume, Low-Value Cases" Alternatives to the High Cost of Litigation. V29, 7 July/August: 135-136.

Sah, M.; Wade, V. (2013). Personalized Concept-based Search and Exploration on the Web of Data using Results Categorization, in P. Cimiano et al. (Ed.) ESWC-2013. The Semantic Web: Semantics and Big Data, LNCS, vol. 7882, pp. 532-547.

Sartor, G. (1994). A Formal Model of Legal Argumentation. Ratio Iuris, 7,2, 117-266.

Sartor, G. (2005). Legal Reasoning: A Cognitive Approach to the Law. Dordrecht: Springer Verlag.

Sartor, G. (2007). Legal Validity: an Inferential Analysis, Florence: EUI Working Papers 2007/24, 1-28. 
Sartor, G. (2009). Understanding and Applying Legal Concepts: An Inquiry on Inferential Meaning, in J. C. Hage and von der Pfordten, D. (Eds.) Concepts in Law (pp. 35-54), Dordrecht, Heidelberg: Springer Verlag.

Sartor, G., Casanovas, P., Biasiotti, M.A., Fernández-Barrera, M. (Eds.) (2011). Approaches to Legal Ontologies. Theories, Domains, Methodologies. LGTS, Dordrecht, Berlin: Springer Verlag.

Sensoy, M., Norman, T., Vasconcelos, W.W., Sycara, K. (2012). OWL-POLAR: A framework for semantic policy representation and reasoning, Web Semantics: Science, Services and Agents on the World Wide Web 12-13, 148-160.

Simon, J. (2010). The entanglement of trust and knowledge on the Web, Ethics and Information Technology 12, 343-355. DOI 10.1007/s10676-010-9243-5.

Slimani, T. (2013). Semantic Description of Web Services, available at http://arxiv.org/pdf/1310.736

Valente, A. \& Breuker,J. (1994). Ontologies: the Missing Link Between Legal Theory and AI \& Law, A. Soeteman (Eds), Legal knowledge based systems JURIX 94: The Foundation for Legal Knowledge Systems (pp. 138-150), Lelystad: Koninklijke Vermande.

Vallbé, J.J., Casellas, N.. (2014) What's the cost of e-Access to Legal Information? A composite indicator. Available at on-line: http://goo.gl/yNn0xz.

Vallbé, J.J. (2014) Measuring the Judicial Power of Regions: A Judicial Regional Authority Index. ECPR Joint Sessions of Workshops 2014, Salamanca. Available at http://www.ecpr.eu/Events/PaperDetails.aspx?PaperID=16452\&EventID=12

Zeleznikow, J. (2011a). Methods for incorporating fairness into the development of an online family dispute resolution environment, Alternative Dispute Resolution Journal 22, $16-21$.

Zeleznikow, J. (2011b). Comparing the Israel-Palestinian Dispute to Australian Family Mediation, Group Decision and Negotiation, DOI 10.1007/s10726-011-9265-3.

Zeleznikow, J.\& Bellucci, E. (2012). "Legal fairness in ADR processes - implications for research and teaching”, Alternative Dispute Resolution Journal 23, 265-273. 